ORIGINAL ARTICLE

\title{
Outcome after operative intervention for traumatic brain injuries in the elderly
}

\author{
Lai-Fung Li, Wai-Man Lui, Heidi Hay-Tai Wong, Wai-Kei Yuen, Gilberto Ka-Kit Leung \\ Division of Neurosurgery, Department of Surgery, Li Ka Shing Faculty of Medicine, The University of Hong Kong, \\ Hong Kong SAR, China
}

\section{ABSTRACT}

Introduction: The management of traumatic brain injuries in the elderly (age $\geq 65$ years) is a constant dilemma. The aim of this study is to investigate for factors that may predict outcome of operative treatment in this group of patients.

Materials and Methods: A retrospective analysis was conducted on 68 elderly patients who had been operated in a designated center from 2006 to 2010. Patients' age, Glasgow Coma score (GCS), pupillary responses, imaging findings, medical conditions, and the use of anticoagulant/antiplatelet agents on patient outcomes were studied.

Results: The overall mortality rate was 55.9\%. Older age, abnormal pupillary response, low GCS, the presence of midline shift and cistern obliteration on computerized tomography were associated with poor survival. Patient aged $75-84$ with normal bilateral pupillary response still had an overall survival rate of $52.6 \%$ and good outcomes (Glasgow outcome score: 4 or 5 ) in $36.8 \%$ of patients. Abnormal pupillary response in at least one eye and preoperative GCS $\leq 12$ were associated with very poor prognosis.

Conclusions: More advanced age was found to be associated with progressively worse outcome. A subgroup patients aged below 85 would survive and could achieve good clinical outcome. The prognosis of those aged over 85 with moderate or severe head injuries was extremely poor.

Key words: Brain injuries, aged, surgical procedures, operative

\section{Introduction}

Age is an important prognostic factor in traumatic brain injury (TBI). ${ }^{[1-4]}$ The management of TBI in the elderly (age $\geq 65$ years according to the World Health Organization) is challenging and wrought with dilemmas. While surgical intervention is indicated for most young patients, justifications for aggressive therapies in the elderly with poor neurological status are subject to debate and controversies. Despite initially successful treatment, the

\begin{tabular}{|l|l|}
\hline \multicolumn{2}{|c|}{ Access this article online } \\
\hline Quick Response Code: & Website: \\
\hline & www.asianjns.org \\
\cline { 2 - 3 } & \\
\hline
\end{tabular}

Address for correspondence:

Dr. Gilberto Ka-Kit Leung, Division of Neurosurgery, Department of Surgery, Li Ka Shing Faculty of Medicine, The University of Hong Kong, Queen Mary Hospital, 102 Pokfulam Road, Hong Kong SAR, China. E-mail: gilberto@hkucc.hku.hk functional outcomes of elderly patients are often unsatisfactory mainly due to significant primary and secondary brain insults, co-existing medical illnesses and poor rehabilitation potential. While over $75 \%$ of those aged 64 or below were able to return to the home after TBI, only around $50 \%$ of those older than 65 could do so. ${ }^{[5]}$

Traumatic brain injury in the elderly is becoming a major concern in view of the rapidly aging populations. According to the WHO, from 2000 to 2050, the world's population aged 60 and above will more than triple from 600 million to 2 billion. ${ }^{[6]}$ In this locality, elderly people accounted for $12.6 \%$ (0.88 million) of the total population in mid-2008. ${ }^{[7]}$ This is expected to increase to $14 \%$ and $27 \%$ by 2016 and 2033 , respectively. ${ }^{[8]}$ In Australia, the number of hospital admissions

This is an open access article distributed under the terms of the Creative Commons Attribution-NonCommercial-ShareAlike 3.0 License, which allows others to remix, tweak, and build upon the work non-commercially, as long as the author is credited and the new creations are licensed under the identical terms.

For reprints contact: reprints@medknow.com

How to cite this article: Li LF, Lui WM, Wong HH, Yuen WK, Leung GK. Outcome after operative intervention for traumatic brain injuries in the elderly. Asian J Neurosurg 2017;12:37-43. 


\section{Li, et al.: Traumatic brain injuries in elderly}

due to TBI in the elderly has been rising over the past 10-year, with the fastest rate of growth seen in those aged above 70. ${ }^{[9]}$ This group of patients is likely to place an increasing demand on medical expertise and healthcare resources. Outcome analysis of our current practice will serve to inform our future decision-makings on clinical, socioeconomical and ethical grounds. Our institution has not used age as a primary selection criterion for providing operative interventions for head-injured patients. In the present study, we reviewed the outcomes of those aged 65 or above who had undergone surgery for TBI, and investigate for factors that may be predictive of their outcomes.

\section{Materials and Methods}

\section{Patient population}

This was a retrospective study of a cohort of consecutive patients aged 65 or above who had undergone neurosurgical operations for TBI over a 4-year period at a designated trauma center. All patients received care from a multidisciplinary hospital trauma team upon admission that included emergency physicians, general and orthopedic surgeons, neurosurgeons, anesthesiologists and intensivists. Clinical management was protocol-driven and followed the Advanced Trauma Life Support guidelines.

\section{Neurosurgical management}

The indications for operative interventions remained the same throughout the study period. Age was not a primary inclusion or exclusion criterion. Patients who had sizable hematoma with thickness $\geq 10 \mathrm{~mm}$ and/or midline shift (MLS) $>5 \mathrm{~mm}$ on computerized tomography (CT) would undergo craniotomy/craniectomy together with intracranial pressure (ICP) monitoring. Patients who did not have significant intracranial mass lesions but whose Glasgow Coma scores (GCSs) were $<9$ would receive endotracheal intubation, artificial ventilation, sedation and external ventricular drainage (EVD) performed in the operating theatre for ICP monitoring and drainage if necessary. The exclusion criteria for surgical intervention included bilateral fixed and dilated pupils and unstable hemodynamics. All patients received perioperative prophylactic antibiotics and anticonvulsant medications. Intravenous mannitol was used for raised ICP. For patients who were taking antiplatelet agents (e.g. aspirin clopidogrel) or anticoagulants (e.g. warfarin), platelet concentrates and fresh frozen plasma would be given prior to and during operations. All patients received postoperative care in the Intensive Care Unit (ICU). Temporary tracheostomy was performed if mechanical ventilation was required for more than 5 days. EVD would be opened for drainage for raised ICP.

\section{Data analysis}

Injury severity was assessed using the admission GCS, pupillary response to light, and CT findings. Severity of head injury was classified based on admission GCS as mild
(GCS =13-15), moderate (GCS =9-12), and severe (GCS =3-8). Patients' premorbid conditions, including histories of stroke, hypertension ( $\mathrm{HT})$, diabetes mellitus (DM), ischemic heart disease, chronic obstructive airway disease, and the use of antiplatelet agent/anticoagulant were recorded. Clinical outcome measures were the GCS and Glasgow outcome score (GOS) upon hospital discharge. Patients with GOS of 4 or 5 were classified as having "good outcome" and those with GOS of 1-3 as "poor outcome." We performed a subgroup analysis for prognostic factors between these two groups, as well as for hospital mortalities (GOS $=1$ versus GOS $=2-5$ ).

\section{Statistical method}

Chi-square and Fisher's exact tests were used for analyzing categorical data. Continuous valuables were analyzed using the Student's t-test. Binary logistic regression was performed using (i) Hospital mortality and (ii) Good/poor outcomes as dependent variables. $P \leq 0.05$ was considered as statistically significant. Statistical tests were performed using IBM SPSS Statistics for Windows, Version 19.0. Armonk, NY: IBM Corp. (IBM, USA).

\section{$\underline{\text { Results }}$}

\section{Patient characteristics}

There were 68 patients, including 45 (66.2\%) men and 23 (33.8\%) women. The mean age was 76.7 years (range: 65-91 years). The most common cause of injury was the fall (70.6\%). The median GCS upon admission was 8 (range: 3-15). Severe, moderate and mild head injuries occurred in 42 (61.8\%), $13(19.1 \%)$ and 13 (19.1\%) patients, respectively. The majority of patients $(n=38)$ had normal pupillary responses, 17 had abnormal responses on one side, and 13 had bilateral abnormal responses (but not both fixed and dilated). Extracranial injuries occurred in 15 (22.1\%) of patients [Table 1]. 27.9\% patients were taking antiplatelet, anticoagulant or both at the time of injury [Table 2].

\section{Computerized tomography findings}

The commonest intracranial lesion was acute subdural hematoma $(\mathrm{ASDH})(n=49$ or $72 \%$ ), followed by traumatic intracerebral hemorrhage (TICH) ( $n=12$ or $17.6 \%$ ). The majority ( $n=49$ or $72.1 \%$ ) of patients harbored more than one pathology; pure ASDH and pure TICH occurred in 16 (23.5\%) and three (4.4\%) patients, respectively. Basal cistern obliteration and significant MLS occurred in 42 (61.8\%) and 46 (67.6\%) of patients, respectively. Of all 68 patients, 61 (89.7\%) received craniotomy or craniectomy, and 7 (10.3\%) underwent EVD insertion only [Table 1].

\section{Patient outcome}

A total of 38 patients died (GOS $=1$ ), yielding a hospital mortality rate of $55.9 \%$. Of the 30 patients who survived, the median GCS upon discharge from hospital was 14 (range: 8-15). GOS of 5 or 4 (i.e. "good outcome") were achieved in 11 (16.2\%) and $6(8.8 \%)$ patients, respectively. $12(17.6 \%)$ were severely 


\section{Li, et al.: Traumatic brain injuries in elderly}

\begin{tabular}{|c|c|c|c|c|c|c|c|}
\hline \multirow[t]{2}{*}{ Patient's demographics } & \multirow[t]{2}{*}{ All patients (68) (\%) } & \multicolumn{3}{|c|}{ Survival } & \multicolumn{3}{|c|}{ Clinical outcome } \\
\hline & & Survive (30) & Died (38) & $P$ & Good outcome (17) & Poor outcome (51) & $P$ \\
\hline Mean age (years) & 76.7 & 74.70 & 78.32 & $0.026^{*}$ & 76.24 & 76.88 & 0.733 \\
\hline \multicolumn{8}{|l|}{ Sex } \\
\hline Male & $45(66.2)$ & 19 & 26 & 0.660 & 12 & 33 & 0.657 \\
\hline Female & $23(33.8)$ & 11 & 12 & & 5 & 18 & \\
\hline \multicolumn{8}{|l|}{ Etiology } \\
\hline RTA & $18(26.5)$ & 7 & 11 & 0.867 & 5 & 13 & 0.653 \\
\hline Fall & $48(70.6)$ & 22 & 26 & & 11 & 37 & \\
\hline Assault & $2(2.9)$ & 1 & 1 & & 1 & 1 & \\
\hline \multicolumn{8}{|l|}{ Severity of head injury } \\
\hline Mild (13-15) & $13(19.1)$ & 12 & 1 & $0.000^{*}$ & 3 & 10 & $0.000^{*}$ \\
\hline Moderate (9-12) & $13(19.1)$ & 6 & 7 & & 2 & 11 & \\
\hline Severe $(\leq 8)$ & $42(61.8)$ & 12 & 30 & & 5 & 37 & \\
\hline Preoperative GCS (median) & 8 & 10.5 & 6 & & 13 & 7 & \\
\hline \multicolumn{8}{|l|}{ Pupillary response } \\
\hline Both normal & $38(55.9)$ & 25 & 13 & $0.000^{*}$ & 14 & 24 & $0.039^{*}$ \\
\hline One abnormal & $17(25)$ & 4 & 13 & & 2 & 15 & \\
\hline Both abnormal & $13(19.1)$ & 1 & 12 & & 1 & 12 & \\
\hline \multicolumn{8}{|l|}{ Injured side } \\
\hline Left & $31(45.6)$ & 14 & 17 & 0.984 & 7 & 24 & 0.850 \\
\hline Right & $28(41.2)$ & 12 & 16 & & 8 & 20 & \\
\hline Both & $9(13.2)$ & 4 & 5 & & 2 & 7 & \\
\hline \multicolumn{8}{|l|}{ MLS } \\
\hline No & $22(32.4)$ & 14 & 8 & $0.025^{*}$ & 9 & 13 & $0.036^{*}$ \\
\hline Yes & $46(67.6)$ & 16 & 30 & & 8 & 38 & \\
\hline \multicolumn{8}{|l|}{ Cistern obliteration } \\
\hline No & $26(38.2)$ & 20 & 6 & $0.000^{*}$ & 14 & 12 & $0.000^{*}$ \\
\hline Yes & $42(61.8)$ & 10 & 32 & r & 3 & 39 & \\
\hline \multicolumn{8}{|l|}{ Operated pathology } \\
\hline ASDH & $49(72)$ & 14 & 35 & $0.001^{*}$ & 11 & 38 & 0.141 \\
\hline $\mathrm{TICH}$ & $12(17.6)$ & 10 & 2 & & 4 & 8 & \\
\hline $\mathrm{EDH}$ & $1(1.5)$ & 1 & o & & 1 & o & \\
\hline Skull fracture & $1(1.5)$ & 1 & o & & 1 & o & \\
\hline Cerebral edema & $1(1.5)$ & o & 1 & & o & 1 & \\
\hline Mixed & $4(5.9)$ & 4 & o & & 1 & o & \\
\hline \multicolumn{8}{|l|}{ Extracranial injury } \\
\hline No & $53(77.9)$ & 23 & 30 & 0.822 & 12 & 41 & 0.399 \\
\hline Yes & $15(22.1)$ & 7 & 8 & & 5 & 10 & \\
\hline
\end{tabular}

All data were analyzed by Chi-square test except mean age was analyzed by student's t-test. * $P \leq 0.05$. RTA - Road traffic accident; GCS - Glasgow Coma score; MLS - Midline shift; ASDH - Acute subdural hematoma; $\mathrm{TICH}$-Traumatic intracerebral hemorrhage; EDH - Extradural hemorrhage

disabled (GOS = 3) and $1(1.5 \%)$ was vegetative (GOS $=2$ ). The survival rate within the 65-74 years age group was $59.3 \%$ ( $n=16$ ), with $25.9 \%$ ( $n=7$ ) achieving good outcome. For the older age group of 75-84 years, the survival rate decreased to $32.4 \%(n=11)$, with good outcome achieved in $23.5 \%(n=8)$ of patients. Outcome was significantly better in patients with mild head injury, with the rates of survival and good outcome being $92.3 \%(n=12)$ and $76.9 \%(n=10)$, respectively $(P \leq 0.001)$ [Table 3 ].

\section{Risk factors for mortalities}

Comparing between patients who survived (GOS $=2-5$ ) and those who died (GOS $=1)$, older age $(P=0.026)$, significant
MLS $(P=0.025)$, cisternal obliteration $(P \leq 0.001)$, one or more abnormal pupillary responses $(P \leq 0.001)$, lower preoperative GCS $(P \leq 0.001)$, and ASDH as the leading pathology $(P=0.001)$, were correlated with hospital mortalities. Gender, laterality of TBI, preexisting medical morbidities, use of antiplatelet or anticoagulant, and coexisting extracranial injuries were not associated with mortality. On binary logistic regression analysis, however, female gender (coefficient: 3.707, odds ratio [OR]: $40.751, P=0.032$ ) was positively correlated with survival. Older age (coefficient: -0.329 , OR: $0.720, P=0.008$ ), cisternal obliteration on CT (coefficient: -3.835 , OR: 0.008 , $P=0.010$ ), ASDH as leading pathology (coefficient: -4.846 , 
Li, et al.: Traumatic brain injuries in elderly

\begin{tabular}{|c|c|c|c|c|c|c|c|}
\hline & \multirow[t]{2}{*}{ All patients (68) (\%) } & \multicolumn{3}{|c|}{ Survival } & \multicolumn{3}{|c|}{ Clinical outcome } \\
\hline & & Survive (30) & Died (38) & $P$ & Good outcome (17) & Poor outcome (51) & $P$ \\
\hline \multicolumn{8}{|l|}{ HT } \\
\hline No & $32(47.1)$ & 17 & 15 & 0.158 & 10 & 22 & 0.262 \\
\hline Yes & $36(52.9)$ & 13 & 23 & & 7 & 29 & \\
\hline \multicolumn{8}{|l|}{ DM } \\
\hline No & $52(76.5)$ & 21 & 31 & 0.264 & 14 & 38 & 0.509 \\
\hline Yes & $16(23.5)$ & 9 & 7 & & 3 & 13 & \\
\hline \multicolumn{8}{|l|}{ IHD } \\
\hline No & $14(20.6)$ & 6 & 8 & 0.915 & 14 & 40 & 0.729 \\
\hline Yes & $54(79.4)$ & 24 & 30 & & 3 & 11 & \\
\hline \multicolumn{8}{|l|}{ Stroke } \\
\hline No & $63(92.6)$ & 28 & 35 & 0.847 & 17 & 46 & 0.180 \\
\hline Yes & $5(7.4)$ & 2 & 3 & & o & 5 & \\
\hline \multicolumn{8}{|l|}{ COAD } \\
\hline No & $61(89.7)$ & 29 & 32 & 0.093 & 16 & 45 & 0.489 \\
\hline Yes & $7(10.3)$ & 1 & 6 & & 1 & 6 & \\
\hline \multicolumn{8}{|c|}{ Antiplatelet/anticoagulant } \\
\hline Anticoagulant & $7(10.3)$ & 3 & 4 & 0.846 & 2 & 5 & 0.870 \\
\hline Antiplatelet & $11(16.2)$ & 5 & 6 & & 2 & 9 & \\
\hline Both & $1(1.5)$ & o & 1 & & o & 1 & \\
\hline None & $49(72.1)$ & 22 & 27 & & 13 & 36 & \\
\hline
\end{tabular}

Chi-square test. HT - Hypertension; DM - Diabetes mellitus; IHD - Ischemic heart disease; COAD - Chronic obstructive airway disease

OR: $0.008, P=0.016)$, moderate (coefficient: -6.895, OR: 0.001, $P=0.016$ ), and severe head injuries (coefficient: -5.446 , OR: $0.004, P=0.009$ ) were negatively associated with survival.

\section{Risk factors for poor clinical outcome}

By categorizing outcomes by GOS (1-3 vs. 4-5), lower preoperative GCS $(P \leq 0.001)$, significant MLS $(P=0.036)$, cisternal obliteration $(P \leq 0.001)$, and pupillary abnormalities $(P=0.039)$ were associated with poor outcome (GOS =1-3). Age and the type of lesion did not show significant correlations. On binary logistic regression analysis, moderate (coefficient: -3.172 , OR: $0.024, P=0.004$ ) and severe head injuries (coefficient: -2.423 , OR: $0.089, P=0.032$ ), cisternal obliteration (coefficient: -3.002 , OR: $0.050, P=0.004$ ) were negatively correlated with good outcome.

\section{Impact of age and severity of head injury}

Elderly patients below 85 -year-old had more than $50 \%$ chance of survival if suffering from mild or moderate head injuries. However, good outcome was achieved in only $15.4 \%(n=2)$ and $11.9 \%(n=5)$ of the respective subgroups of patients. This compared with a $76.9 \%$ rate of a good outcome in those suffering from mild head injury. For the age $\geq 85$, there was no survivor after moderate to severe head injuries. Overall, mild head injury had the highest survival rate and was most likely to be associated with good outcome $(P \leq 0.001)$ [Table 3].

Impact of age and pupillary responses

Overall, normal bilateral response was associated with better survival $(P \leq 0.001)$ as well as clinical outcome ( $P=0.039$ ) [Table 4]. Normal bilateral pupillary response was significantly associated with higher survival rates in the $65-74(P=0.002)$ and $75-84(P=0.016)$ age groups, as well as good outcome in the $75-84$ group $(P=0.039)$. For the age $\geq 85$ years, the patient number was too small to draw significant conclusion. The presence of one abnormal pupil reduced by around one-third the overall chance of survival (from 65.8\% to $23.5 \%$ ) and good outcome (from $36.8 \%$ to $11.8 \%)$. Provided both pupils were normal, age $65-74$ had a much higher survival rate of $92.3 \%$ compared with around $50 \%$ in age $75-84$ and age 85 years, which again stressed the importance of age.

\section{Impact of age and computerized tomography findings}

Of the 36 patients who had coexisting MLS and cisternal obliteration on CT, only nine (25\%) survived, and three $(8.3 \%)$ had good clinical outcome. Of the 10 patients who had MLS without cistern obliteration, seven (70\%) survived and five (50\%) had a good outcome. Six patients had cistern obliteration without MLS, only one survived and had a poor outcome.

\section{Discussion}

Fall is the most common case of TBI in the elderly, and around $13 \%$ of these patients would require hospital admission. ${ }^{[10]}$ Over $70 \%$ of our patients suffered from the fall that was consistent with the findings from other reports..$^{[9,11,12]}$ Similarly, ASDH was the most common pathology and was the leading cause of mortality. ${ }^{[9,12]}$ Age is a well-recognized prognostic 


\section{$\mathrm{Li}$, et al.: Traumatic brain injuries in elderly}

Table 3: Severity of head injury versus survival rate and good outcome rate in different age groups

\begin{tabular}{|c|c|c|c|c|}
\hline $\begin{array}{l}\text { Severity of head } \\
\text { injury }\end{array}$ & Mild (\%) & $\begin{array}{l}\text { Moderate } \\
\text { (\%) }\end{array}$ & Severe (\%) & Total (\%) \\
\hline \multicolumn{5}{|l|}{$\begin{array}{l}\text { Age } 65-74 \\
\text { years }(n=27)\end{array}$} \\
\hline Survived & $4 / 4(100.0)$ & $2 / 4(50.0)$ & $10 / 19(52.6)^{*}$ & $16 / 27(59 \cdot 3)$ \\
\hline Good outcome & $3 / 4(75.0)$ & $1 / 4(25.0)$ & $3 / 19(15.8)$ & $7 / 27(25.9)$ \\
\hline \multicolumn{5}{|l|}{$\begin{array}{l}\text { Age } 75-84 \\
\text { years }(n=34)\end{array}$} \\
\hline Survived & $5 / 6(83 \cdot 3)$ & $4 / 8(50.0)$ & $2 / 20(10.0)^{* *}$ & $11 / 34(32.4)$ \\
\hline Good outcome & $5 / 6(83 \cdot 3)$ & $1 / 8(12.5)$ & $2 / 20(10.0)^{* * *}$ & $8 / 34(23.5)$ \\
\hline \multicolumn{5}{|l|}{$\begin{array}{l}\text { Age } \geq 85 \\
\text { years }(n=7)\end{array}$} \\
\hline Survived & $3 / 3(100.0)$ & $0 / 1(0.0)$ & $0 / 3(0.0)^{*}$ & $3 / 7(42.9)$ \\
\hline Good outcome & $2 / 3(66.7)$ & $0 / 1(0.0)$ & $0 / 3(0.0)$ & $2 / 7(28.6)$ \\
\hline \multicolumn{5}{|l|}{ Total } \\
\hline Survived & $12 / 13(92.3)$ & $6 / 13(46.2)$ & $12 / 42(28.6)^{* * *}$ & \\
\hline Good outcome & $10 / 13(76.9)$ & $2 / 13(15.4)$ & $5 / 42(11.9)^{* * *}$ & \\
\hline
\end{tabular}

Table 4: Pupillary response versus survival and clinical outcome in different age group

\begin{tabular}{lcccc}
\hline $\begin{array}{l}\text { Pupillary } \\
\text { response }\end{array}$ & $\begin{array}{c}\text { Both } \\
\text { normal (\%) }\end{array}$ & $\begin{array}{c}\text { One } \\
\text { abnormal (\%) }\end{array}$ & $\begin{array}{c}\text { Both } \\
\text { abnormal (\%) }\end{array}$ & Total (\%) \\
\hline $\begin{array}{l}\text { Age 65-74 } \\
\text { years ( } n=27)\end{array}$ & & & & \\
$\quad$ Survived & $12 / 13(92.3)$ & $3 / 7(42.9)$ & $1 / 7(14.3)^{* *}$ & $16 / 27(59.3)$ \\
$\quad$ Good outcome & $5 / 13(38.5)$ & $1 / 7(14.3)$ & $1 / 7(14.3)$ & $7 / 27(25.9)$ \\
$\begin{array}{l}\text { Age } 75-84 \\
\text { years ( } n=34)\end{array}$ & & & & \\
$\quad$ Survived & $10 / 19(52.6)$ & $1 / 10(10.0)$ & $0 / 5(0)^{*}$ & $11 / 34(32.4)$ \\
$\quad$ Good outcome & $7 / 19(36.8)$ & $1 / 10(10.0)$ & $0 / 5(0)^{*}$ & $8 / 34(23.5)$ \\
$\begin{array}{l}\text { Age } \geq 85 \\
\text { years ( } n=7)\end{array}$ & & & & \\
$\quad$ Survived & $3 / 6(50.0)$ & $\mathrm{N} / \mathrm{A}$ & $0 / 1(0.0)$ & $3 / 7(42.9)$ \\
$\quad$ Good outcome & $2 / 6(33.3)$ & $\mathrm{N} / \mathrm{A}$ & $0 / 1(0.0)$ & $2 / 7(28.6)$ \\
Total & & & & \\
$\quad$ Survived & $25 / 38(65.8)$ & $4 / 17(23.5)$ & $1 / 13(7.7)^{* * * *}$ & \\
$\quad$ Good outcome & $14 / 38(36.8)$ & $2 / 17(11.8)$ & $1 / 13(7.7)^{*}$ & \\
\hline
\end{tabular}

Chi-square test. ${ }^{*} P \leq 0.05, * * P \leq 0.01, * * * P \leq 0.001$

factor for TBI. However, for patients with aged above 65, more detailed analysis is lacking as most reported studies focused mainly on comparisons between young (age $<65$ years) and elderly patients (age $\geq 65$ years). ${ }^{[11,13,14]}$ It remains unclear whether and how more advanced age within the elderly group would affect clinical outcome. Lau et al. had reported no difference in mortality rates between different age groups. Age only affected the need of rehabilitation. ${ }^{[15]}$ However, in that study, patients were divided into those younger than 50 and those older than 80, with 30-day mortality as the main treatment outcome. Mortalities beyond 30-day due to complications, which were more common in the elderly, were not assessed.
With our increasingly aging populations, more in-depth stratifications are urgently needed. We found that, within the elderly population, more advanced age itself was a risk factor for mortality but was not found to be an independent risk factor for poor outcome. Patients aged 75-84 with normal bilateral pupillary responses could achieve good survival in 52.6\% of cases, and around one-third had good clinical outcome. For patients age $\geq 85$ years old, provided they had normal pupils upon presentation, one-third of them could have good clinical outcome. Despite our small sample size, it may be concluded that even for very advance age, operative interventions may still provide benefit. On the other hand, loss of pupillary response of at least one eye in aged $\geq 85$ signified extremely poor prognosis.

Preoperative GCS was found to be a major prognostic factor as reported by other previous studies..$^{[1,13,15,16]}$ Good clinical outcome and high survival rates were observed for patients with minor TBI (GCS $=13-15)$. With GCS below 12, the rates of both good clinical outcome and survival decreased markedly, particularly in the over - 85 age group in which the chance of survival was minimal. Pupillary response to light was another important factor. It has been shown that in young patients, normal pupillary responses were associated with an overall mortality rate of $23.5 \%$, which compared with up to $79.7 \%$ when both pupils were abnormal. ${ }^{[4]}$ In addition, good pupillary response was also associated with good GOS.

Significant MLS and cisternal obliteration on CT are known to predictive of poor outcome. ${ }^{[16]}$ In Marshall's study, cistern obliteration (Diffuse Injury III) and MLS (Diffuse Injury IV) were associated with mortality rates of $34 \%$ and $56.2 \%$, respectively. ${ }^{[17]}$ In comparison, five out of six of our patients with cisternal obliteration on the initial CT died. The mortality rate of those that had MLS with or without co-existing cistern obliteration was $65.2 \%$. The higher mortality rates in our cohort may be due to the patients' more advanced age as well as differences in their intracranial pathologies. Marshall's grading focused on diffuse brain injury, whereas ASDH was the leading pathology in our cohort. Another recent study on patients with intra-cranial hematomas that required craniotomy also showed that MLS was associated with a higher mortality rate and the lower chance to return to preoperative baseline. ${ }^{[10]}$

It was somewhat surprising that medical comorbidities were not associated with mortalities in the present study. Similar findings have been reported, which showed that coexisting DM, HT and coronary artery disease did not increase mortality, the need of rehabilitation nor ability to return to baseline. ${ }^{[15]}$ DM and coronary artery disease were associated with longer ICU and hospital stay while HT only affected hospital stay 


\section{$\mathrm{Li}$, et al.: Traumatic brain injuries in elderly}

without prolong the ICU stay. ${ }^{[15]}$ These may be due to the successful management of these co-morbidities in modern ICU and/or the overwhelming influences from other prognostic factors. It must be emphasized that our study only captured a limited number of preexisting disease. Other common conditions such as renal disease, cerebral degeneration, malignancies that previously considered terminal but are now becoming chronic illnesses, may yet have a significant impact on patient outcome.

The effect of concurrent antiplatelet agents and anticoagulants be controversial. It had been shown that anticoagulant use was associated with a $38 \%$ mortality rate, compared with $8 \%$ in nonusers after TBI. ${ }^{[18]}$ Another retrospective study also demonstrated preinjury anticoagulation use was predictive of survival. ${ }^{[19]}$ In contrast, it has been shown that clopidogrel, aspirin or warfarin (CAW) did not result in higher mortality rates. ${ }^{[3]}$ Others reported that only clopidogrel had negative impact on survival but not aspirin or warfarin. ${ }^{[20]}$ The discrepancy of these reports may result from a number of factors. Firstly, the definition of anticoagulation was not uniform. Some authorities considered warfarin, clopidogrel and aspirin as a single entity of anticoagulation, or CAW. ${ }^{[3,21]}$ Others included only warfarin under anticoagulants. ${ }^{[18,20]}$ Second, the effects of these medications were not always studied separately. Mortality was found to be related to the patients' coagulation profiles such as the International Normalizing ratio (INR). ${ }^{[12,19]}$ An INR greater than two was associated with higher mortality, while warfarin users with INR below two had no difference with control. ${ }^{[21]}$ Third, many reported studies included all patients with TBI in which the majority of patients suffered from mild head injury without the need for operative interventions. In contrast, study focused on patients who required surgery like ours had a high percentage of patients with severe head injury. ${ }^{[15]}$ Our results were compatible with studies that only included patients undergoing operative intervention, and we found that the use of anticoagulant did not increase mortality rate. In that study, they showed that the anticoagulant only increased complication rate and length of hospital stay.

The main limitations of our study included a lack of comparison with patients on nonoperative management. This latter group included patients with good GCS whose intracranial mass lesions showed borderline mass effect on CT. The decision to provide operative interventions were primarily based on individual physicians' clinical judgments and this may result in sampling bias for our study. Another limitation was the lack of longitudinal follow-up on delayed mortalities and survivors' functional outcome and quality-of-life. Our sample size is small, only one single institution was involved, and there were too few patients in the group with age over 85-year-old. The patients were highly heterogeneous in terms of their intracranial pathologies. The length of stay and cost of hospital, as well as the impact on the patients' families and communities, were also not addressed as many survivors were lost follow-up as they moved to mainland China for care after discharge.

In conclusion, age is an important prognostic factor in TBI. Within the elderly population, more advanced age was found to be associated with progressively worse outcome. However, a subgroup patients aged below 85 would survive and could achieve good clinical outcome, including those with moderate and severe TBI. The prognosis of those aged over 85 with moderate or severe head injuries was extremely poor. The severities of injury, pupillary reactions and CT findings contributed as other significant factors which should be considered when during clinical decision-making.

\section{Financial support and sponsorship}

Nil.

\section{Conflicts of interest}

There are no conflicts of interest.

\section{$\underline{\text { References }}$}

1. Ono J, Yamaura A, Kubota M, Okimura Y, Isobe K. Outcome prediction in severe head injury: Analyses of clinical prognostic factors. J Clin Neurosci 2001;8:120-3.

2. Pompucci A, De Bonis P, Pettorini B, Petrella G, Di Chirico A, Anile C. Decompressive craniectomy for traumatic brain injury: Patient age and outcome. J Neurotrauma 2007;24:1182-8.

3. Fortuna GR, Mueller EW, James LE, Shutter LA, Butler KL. The impact of preinjury antiplatelet and anticoagulant pharmacotherapy on outcomes in elderly patients with hemorrhagic brain injury. Surgery 2008;144:598-603.

4. Chamoun RB, Robertson CS, Gopinath SP. Outcome in patients with blunt head trauma and a Glasgow Coma Scale score of 3 at presentation. J Neurosurg 2009;111:683-7.

5. Bhullar IS, Roberts EE, Brown L, Lipei H. The effect of age on blunt traumatic brain-injured patients. Am Surg 2010;76:966-8.

6. World Health Organization. What are the public health implications of global ageing? Available from: http://www.who.int/features/qa/42/en/ index.html. [Last accessed on 2012 Oct 13].

7. Census and Statistics Department. The Government of the Hong Kong Special Administrative Region. The 2006 Population Census. Available from: http://www.bycensus2006.gov.hk/en/data/data2/index. htm. [Last accessed on 2012 Oct 13].

8. Census and Statistics Department. The Government of the Hong Kong Special Administrative Region. The 2001 Population Census. Available from: http://www.censtatd.gov.hk/major_projects/2001_ population_census/index.jsp. [Last accessed on 2012 Oct 13].

9. Harvey LA, Close JC. Traumatic brain injury in older adults: Characteristics, causes and consequences. Injury 2012;43:1821-6.

10. Yu WY, Hwang HF, Hu MH, Chen CY, Lin MR. Effects of fall injury type and discharge placement on mortality, hospitalization, falls, and ADL changes among older people in Taiwan. Accid Anal Prev 2013;50:887-94.

11. Depreitere B, Meyfroidt G, Roosen G, Ceuppens J, Grandas FG. Traumatic brain injury in the elderly: A significant phenomenon. Acta Neurochir Suppl 2012;114:289-94.

12. Gaetani P, Revay M, Sciacca S, Pessina F, Aimar E, Levi D, et al. Traumatic brain injury in the elderly: Considerations in a series of 103 patients older than 70. J Neurosurg Sci 2012;56:231-7.

13. Petridis AK, Dörner L, Doukas A, Eifrig S, Barth H, Mehdorn M. Acute 


\section{Li, et al.: Traumatic brain injuries in elderly}

subdural hematoma in the elderly; clinical and CT factors influencing the surgical treatment decision. Cent Eur Neurosurg 2009;70:73-8.

14. Moore MM, Pasquale MD, Badellino M. Impact of age and anticoagulation: Need for neurosurgical intervention in trauma patients with mild traumatic brain injury. J Trauma Acute Care Surg 2012;73:126-30.

15. Lau D, El-Sayed AM, Ziewacz JE, Jayachandran P, Huq FS, Zamora-Berridi GJ, et al. Postoperative outcomes following closed head injury and craniotomy for evacuation of hematoma in patients older than 80 years. J Neurosurg 2012;116:234-45.

16. Servadei F. Prognostic factors in severely head injured adult patients with acute subdural haematoma's. Acta Neurochir (Wien) 1997;139:279-85.

17. Marshall LF, Marshall SB, Klauber MR, Van Berkum Clark M, Eisenberg $\mathrm{H}$, Jane JA, et al. The diagnosis of head injury requires a classification based on computed axial tomography. J Neurosurg 1991;75:S14-20.

18. Mina AA, Knipfer JF, Park DY, Bair HA, Howells GA, Bendick PJ. Intracranial complications of preinjury anticoagulation in trauma patients with head injury. J Trauma 2002;53:668-72.

19. Franko J, Kish KJ, O’Connell BG, Subramanian S, Yuschak JV. Advanced age and preinjury warfarin anticoagulation increase the risk of mortality after head trauma. J Trauma 2006;61:107-10.

20. Wong DK, Lurie F, Wong LL. The effects of clopidogrel on elderly traumatic brain injured patients. J Trauma 2008;65:1303-8.

21. Pieracci FM, Eachempati SR, Shou J, Hydo LJ, Barie PS. Degree of anticoagulation, but not warfarin use itself, predicts adverse outcomes after traumatic brain injury in elderly trauma patients. J Trauma 2007;63:525-30. 